In: ISMÉRIO, Clarisse (Org.). Patrimônio Cultural: simbolismos, intertextualidades e polifonias [livro eletrônico]. São Paulo: Vecher, 2021. Disponível em: <https://doi.org/10.47585/9786599324215>.

\title{
A salvaguarda do patrimônio literário: edições interpretativas da produção dispersa de Innocencio Galvão de Queiroz
}

\author{
Gilson Antunes da Silva ${ }^{1}$, Ana Beatriz Santos Conceição ${ }^{2}$ \\ e Carlos Abraão Negrão Silva \\ doi.org/10.47585/9786599324215.3
}

Apresentamos o projeto "Entre a memória, a salvaguarda e o texto: Innocencio Galvão de Queiroz e sua dispersa produção ficcional", desenvolvido como pesquisa no Instituto Federal de Educação, Ciência e Tecnologia Baiana (IF Baiano, Campus Valença) entre ao anos 2019 a 2020, a fim de evidenciar como, por meio de edições interpretativas, contribuímos para a preservação e a divulgação do patrimônio literário do Baixo Sul da Bahia. Tomamos como corpus de investigação jornais publicados no século XX na cidade de Valença, as revistas $\mathrm{O}$ Tico-tico, $\mathrm{O}$ malho e Beira-Mar, editadas no Rio de Janeiro no século XX, além de duas Miscelâneas em que eram colecionados textos e notícias sobre a família Queiroz. As edições realizadas contribuem para a reintrodução de textos do autor no cenário literário local, reavivando sua memória e valorizando a sua produção.

Palavras-chave: Patrimônio literário; Galvão de Queiroz; Filologia; Salvaguarda; Edição interpretativa.

\footnotetext{
1 Doutor em Literatura e Cultura (UFBA), Mestre em Letras e Linguística (UFBA), Especialista em Língua Portuguesa e Literatura Brasileira (FACCEBA), em Ensino de Língua e Literaturas de Língua Portuguesa (UNIMES), em Teoria da Psicanálise de Orientação Lacaniana (BAHIANA/IPBA), Licenciado em Letras (UNEB) e Bacharel em Filosofia (UCSal). Professor do IF Baiano (Valença), membro do Grupo de Pesquisa em Linguagens, Culturas e Ambientes (GLICAM) e da Academia Valenciana de Educação, Letras e Artes (AVELA), http://lattes.cnpq.br/7484310646564871, e-mail: gilsonfi@bol.com.br.

2 Aluna do último ano do curso Técnico Integrado em Agroecologia do Instituto Federal Baiano (Campus Valença), pesquisadora CNPq, http://lattes.cnpq.br/5632584923870080, e-mail: a.beatrizsc03@gmail.com.

3 Aluno do último ano do curso Técnico Integrado em Agroecologia do Instituto Federal Baiano (Campus Valença), pesquisador CNPq, http://lattes.cnpq.br/9839768351473511, e-mail: abraaonegrao1@gmail.com.
} 


\section{Introdução}

O interesse pelos arquivos por parte da crítica literária tem crescido ultimamente no sentido de se buscarem, nesses espaços, marcas ou pistas para a compreensão do texto via estudo do autor. A abertura promovida pela literatura comparada no âmbito dos estudos literários é uma das responsáveis por estabelecer esse diálogo com outros espaços e/ou suportes de compreensão do fenômeno literário. Nesse sentido, diluíram-se as fronteiras disciplinares, relativizando os saberes particularizados e fechados em uma única direção, além de se promover uma outra posição metodológica frente ao material de pesquisa. Por esse viés, adota-se uma perspectiva de estudo também voltada para materiais existentes nos acervos literários - o estudo das fontes primárias - imprimindo novo olhar sobre a recuperação do texto e da memória. Dessa estratégia de investigação, surgem as biografias literárias, edições críticas, publicações de textos inéditos, edições de obras raras, organização de antologias, além da produção de um conhecimento não monumental (SOUZA, 2002).

Voltar-se para esses lugares onde os textos são depositados ou mesmo esquecidos significa restituir a esses mesmos textos sua gestualidade perdida de escritura, sua dinâmica de transformações, acréscimos, subtrações e apropriações. Trata-se de um ato de recuperação mnemônica (COLOMBO, 1991), em que se traz o texto para o presente, revitalizando sua potencialidade e infundindo outra vida naquilo que dele é resgatado.

A sedução dos arquivos sempre exerceu grande fascínio sobre um outro grupo de estudiosos, os filólogos ou amantes da palavra. A busca pelo texto em sua materialidade os leva a esses ambientes, com o objetivo de preservá-lo e restituí-lo em sua forma original, para que possa ser estudado em seus variados aspectos: linguístico, literário, crítico-textual, sócio-histórico, etc. O surgimento da própria Filologia está diretamente aliado a esses lugares de memória. Segundo César Nardelli Cambraia (2005), os primeiros trabalhos da Crítica Textual no Ocidente estão, por exemplo, situados em torno da Biblioteca de Alexandria em que se formou um centro de estudos onde se reuniam estudiosos de diversas áreas. Ao longo de seu desenvolvimento, a Filologia jamais se afastara desses centros de guarda da memória. Com o desenvolvimento da Crítica Genética, esse apego a arquivos, museus, bibliotecas particulares e memoriais permanecera em voga. Como seu objeto são "os manuscritos literários, na medida em que trazem o traço de uma dinâmica" (GRÉSILLON, 2002, p. 147), a Crítica Genética utiliza-se de uma gama heterogênea de fontes.

A partir dos anos dois mil, foi muito intensa a publicação de autores locais na cidade de Valença (Bahia) ${ }^{4}$. Surgem importantes antologias organizadas pelo escritor Araken Vaz Galvão e muitas publicações autorais, revelando autores como Alfredo Gonçalves de Lima Neto, Rosângela Góes, o próprio Araken Vaz Galvão, Moacir Saraiva, Amália Grimaldi, Ricardo Vidal, Mustafá Rosenberg, Ângelo Paraíso Martins, Macária Andrade, etc. O que se produziu antes disso pouco se sabe e se conhece. Encontram-se, nas bibliotecas locais, dois livros do poeta Otávio Mota publicados

4 Valença é um município situado no território do Baixo Sul da Bahia com área de $1.123,975 \mathrm{~km}^{2}$ e com uma população de, aproximadamente, 97.233 pessoas. 
na década de oitenta: Pensar fluidos (1986) e Apocalipse Man (1987). Nomes como José Malta, Cícero Mendes, João Batista Cerne, Manoel Ribeiro, Jacob Campos, Álvaro Maciel, Nathan Coutinho, Newton Libertador, Galvão de Queiroz, Ribeiro Libertador e Fábio Luz foram vítimas do apagamento arquivista e desapareceram, de certa forma, do campo literário baiano.

Essa pulsão de amnésia, expressão cunhada pelo filósofo Jacques Derrida em Mal de arquivo (2001), atravessa a história cultural da cidade de Valença e se digladia com outra pulsão de potência semelhante, que tenta resistir a essa força de esquecimento. A memória se mantém entre essas duas forças antagônicas, isso porque:

A memória é a vida, sempre carregada por grupos vivos e, nesse sentido, ela está em permanente evolução, aberta à dialética da lembrança e do esquecimento, inconsciente de suas deformações sucessivas, vulnerável a todos os usos e manipulações, susceptível de longas latências e de repentinas revitalizações. (NORA, 1993, p. 9).

É nesse contexto que surge este trabalho, resultado de uma pesquisa desenvolvida no Instituto Federal de Educação, Ciência e Tecnologia Baiano (IF Baiano, Campus Valença) e de uma das metas do Grupo de Pesquisa Linguagens, Culturas e Ambientes - GLICAM. Na linha de pesquisa Literatura e Cultura do Baixo Sul, objetivamos estudar as representações literárias e culturais do Baixo Sul do Estado da Bahia, investigar as produções literárias de seus autores, a fim de preservar, divulgar e valorizar o patrimônio literário, escritural, linguístico e cultural da região e do Estado, além de editar, publicar e analisar, sob diferentes perspectivas teóricas, as produções literárias e culturais criadas a partir do século XIX. Nasce, por sua vez, do desejo de trazer à cena literária autores esquecidos no tempo e recuperar essas memórias desbotadas. Aqui nos debruçamos sobre os textos dispersos de Innocencio Galvão de Queiroz, poeta, cronista, contista, tradutor, crítico literário e amante da palavra.

Galvão de Queiroz nasceu em Valença (BA), em 29 de julho de 1904. Foi secretário e professor do Colégio Nacional em Paraíba do Sul. Em 1935, ingressou na redação da revista O Malho, fazendo parte até se aposentar em 1965. Durante 30 anos, foi redator e arquivista de O Malho, Ilustração Brasileira, além de dirigir O Tico-Tico, Tiquinho, Cirandinha e os seus respectivos Almanaques. Colaborou com diversos jornais nacionais e locais, traduziu algumas dezenas de livros do francês e do espanhol para a Editora Vechi. Em 1933, publicou Caíva: contos, pela Editora do Globo que, no ano seguinte, conquistou o primeiro lugar no Concurso da Academia Brasileira de Letras. Além desse livro, o autor escreveu outros infantis: Reportagens de Pitusquinho (1942?); Os sinais misteriosos (1945?); A árvore que falava (s.d.); e O pinguim que fugiu do gelo (1977), editados pela Biblioteca Infantil de O Tico-Tico. Faleceu em 10 de janeiro de 1977, na cidade do Rio de Janeiro, deixando uma série de textos dispersos em jornais e revistas para os quais colaborou ao longo de sua vida.

Muitos de seus textos publicados em jornais e revistas não foram reunidos em livros e estão desaparecendo ao longo dos anos. Isso faz com que o grande público não conheça os outros perfis autorais de Galvão de Queiroz para além daqueles desenhados nos seus livros de contos e de literatura infantil. Nesse sentido, desenvolvemos um projeto que buscasse recompor esses textos dispersos. Buscamos, portanto, em primeiro lugar, resgatar esses textos do passado para que não desapareçam e, 
a partir daí, possamos torná-los acessíveis aos leitores; em segundo, preservar a integridade dos documentos importantes da nossa cultura e das literaturas valenciana e baiana, pela importância de restabelecer os monumentos literários, históricos na sua originalidade; em terceiro, conservar esses monumentos da memória cultural das corrupções do tempo; e, por fim, preservar o patrimônio literário, escritural, linguístico e cultural da cidade e, por conseguinte, do Estado da Bahia. Vale ressaltar ainda a importância do autor para as Letras Nacionais. Trata-se, também, de um escritor premiado nacionalmente, diretor/redator de umas das maiores revistas de circulação nacional e, em virtude disso, não pode ser esquecido. Recuperar seus textos dispersos implica também dar a devida valorização que um autor dessa estirpe merece, para que os seus conterrâneos possam ler seu passado e compreender o presente, seja à luz de suas crônicas, seja à luz de seus contos e poemas.

Objetivamos, neste texto, evidenciar como desenvolvemos trabalho de preservação do patrimônio literário na cidade de Valença-BA, valendo-se da Filologia Textual para editar, na perspectiva da edição interpretativa, textos de Galvão de Queiroz dispersos em arquivos e acervos particulares. Dividimos este texto em duas partes: na primeira, apresentamos o projeto com seus objetivos e sua metodologia e contextualizamos a principal teoria usada no seu desenvolvimento; na segunda, apresentamos os resultados do projeto, trazendo um exemplo de edição interpretativa e evidenciando a sua importância para a preservação do patrimônio literário.

\section{O projeto de salvaguarda}

O projeto intitulado "Entre a memória, a salvaguarda e o texto: Innocencio Galvão de Queiroz e sua dispersa produção ficcional” foi desenvolvido no IF Baiano (Campus Valença) entre os anos de 2019 e 2020 e teve apoio do Conselho Nacional de Desenvolvimento Científico e Tecnológico (CNPq). Trata-se da chamada Interna PROPES No03/2019 do Programa Institucional de Bolsas de Iniciação Científica PIBIC - Ensino Médio/CNPq/IF Baiano. Os bolsistas Ana Beatriz Santos Conceição e Carlos Abraão Negrão Silva, coordenados por Gilson Antunes da Silva, desenvolveram as pesquisas em acervos físicos e digitais, a fim de localizar e recuperar textos de Galvão de Queiroz. Este projeto foi premiado na VII Mostra de Iniciação Científica do Instituto Federal Baiano - MIC, no I Congresso de Ensino e Pesquisa do IF Baiano (2020), como o melhor projeto de Iniciação Científica Ensino Médio. Objetivou-se, com esse projeto, editar textos ficcionais desse autor, de maneira que se pudesse organizar e recuperar seu material disperso, a fim de salvaguardar esse material do esquecimento e da destruição temporal. Além disso, pretendeu-se, após a organização desse material disperso, fazer alguns estudos de cunho crítico-analítico para oferecer ao leitor uma perspectiva de leitura literária da ficção do autor. Além desse objetivo central, elegemos outros secundários para nossa pesquisa, a saber: coletar os textos dispersos de Galvão de Queiroz, publicados em jornais, revistas e cadernos (manuscritos); realizar edição interpretativa desses textos, a 
fim de preservá-los do esquecimento; organizar esses textos editados e apresentar uma leitura crítica desse material com base na Crítica e na Teoria Literárias; classificar esses textos a partir da teoria dos gêneros textuais e literários; apresentar uma biografia do autor com base nos materiais encontrados no corpus da pesquisa; apresentar, junto à edição interpretativa, alguns fac-símiles de textos mais significativos do autor.

Para alcançar nossos objetivos, utilizamos, como material básico desta pesquisa, exemplares de jornais depositados no Memorial da Câmara Municipal da cidade de ValençaBA, no Centro de Cultura Olívia Barradas (Valença - BA), no Instituto Cultural Euzedir e Araken Vaz Galvão (Valença - BA), no Instituto Histórico e Geográfico da Bahia (Salvador - BA). Aí se encontram peças dos principais jornais que circularam na cidade de Valença durante o século XX. No Memorial, estão depositados oito jornais diferentes que dão conta da vida literária, política, cultural, econômica e social da cidade, desde a primeira metade do século XX até os finais dos anos noventa. O mais abundante em exemplares é o Jornal Folha da Cidade, fundado na década de 1960. Dele existem em torno de 53 edições, cobrindo os anos de 1966 a 1973. O segundo maior em edições depositadas é o Manacá com sete delas (entre os anos de 1977 a 1991). Existem ainda edições de A semana (três, 1940 a 1962), O município (sete, de 1942 a 1945), O comércio (duas, de 1935), Jornal de Valença (duas, de 1963 e 1964), O Aráivid (três, de 1971) e alguns fragmentos do Jornal Valença Oficial (1942). Já no Centro de Cultura, encontram-se quatro jornais do século XX: Jornal de Valença (1963, 34 edições); O Município (1938-42, 13 edições); A Semana (1954 e 58, duas edições); Folha da Cidade (1970, 3 edições). Na Fundação Cultural Euzedir e Araken Vaz Galvão, estão depositados seis jornais valencianos: Caduceu (1965, 1 edição); Folha da Cidade (1965, 4 edições); A Semana (1949, 4 edições); O Aráivid (1971, 2 edições); Tribuna do Povo (1921, 5 edições); O Clarim (1915, 8 edições). Por fim, no Instituto Histórico e Geográfico da Bahia, encontram-se depositados 4 jornais editados na cidade de Valença: Correio Valenciano (1933-36, 6 edições); O Município (1933-38, 83 edições); O Provisório (1933, 27 edições) e O Comércio (1931-35, 41 edições). Além desses jornais, nosso corpus de investigação abarcou duas coletâneas intituladas pela dona Regina Queiroz (sobrinha do autor objeto desta pesquisa) de Miscelânea. Trata-se de dois cadernos em que os familiares colecionavam manuscritos, fotografias e recortes de jornais referentes à família. Nas duas Miscelâneas, encontra-se um verdadeiro arquivo da família Queiroz cuja memória é preservada com muito cuidado por dona Regina, guardiã desse tesouro. Há, nesses cadernos, textos manuscritos de Galvão de Queiroz, além de recortes de jornais com textos que foram escritos por ele. Por fim, o corpus dessa pesquisa abrangeu as revistas Tico Tico e O malho (1935 a 1977) das quais Galvão de Queiroz era diretor e colaborador. A pesquisa foi feita na Hemeroteca digital da Biblioteca $\mathrm{Nacional}^{5}$, em que se encontram disponíveis exemplares dessas revistas para livre acesso.

5 Disponível em: <http://hemerotecadigital.bn.br/acervo-digital/tico-tico/153079>. Disponível em: <http://objdigital.bn.br/acervo_digital/div_periodicos/malho/anuario_malho.htm> 
Figura 1: Cabeçalho de jornais valencianos e revistas cariocas usadas como corpus de pesquisa.

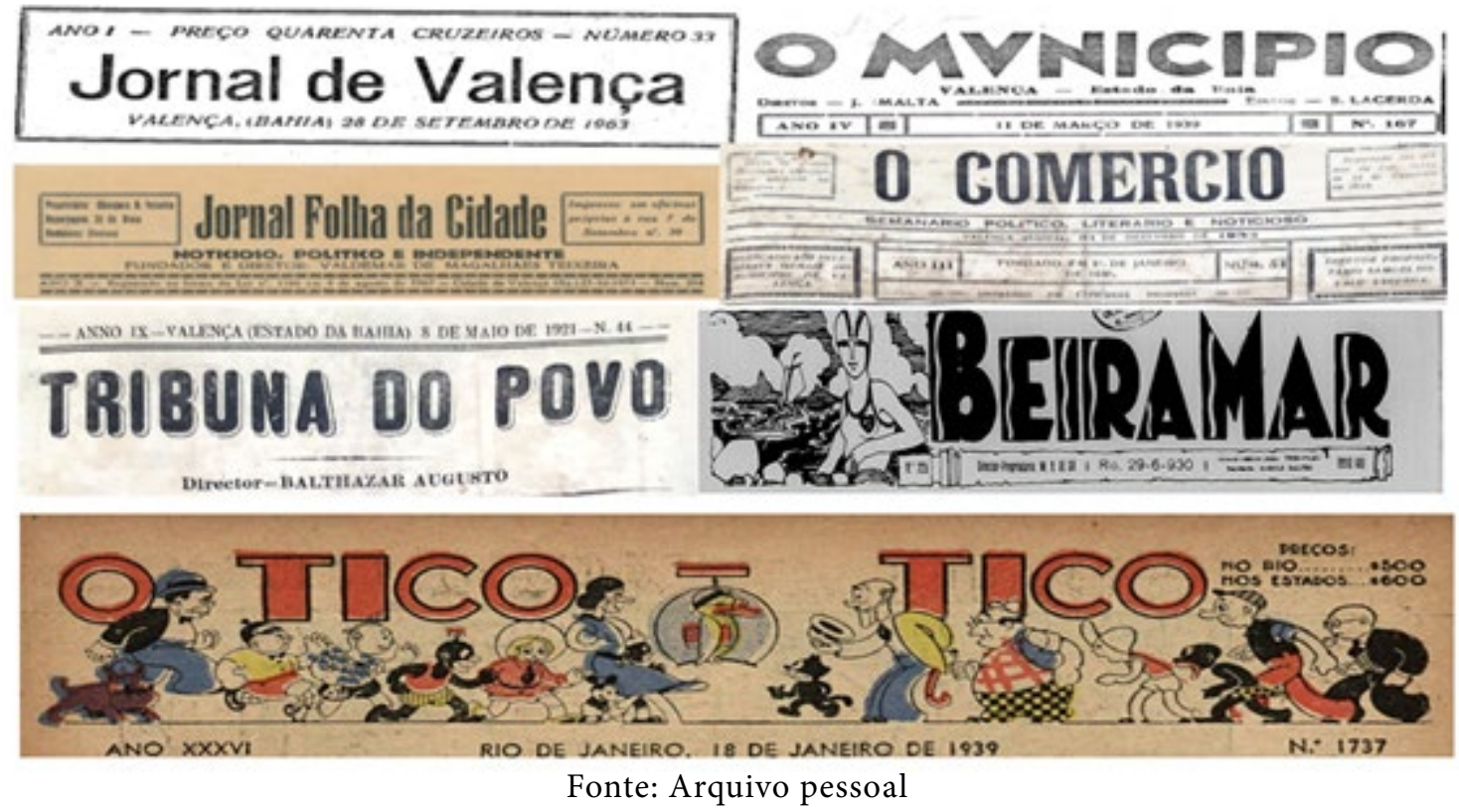

Ao longo da pesquisa, ampliamos o corpus, inserindo mais uma revista digital, uma vez que descobrimos uma série de textos de Galvão de Queiroz aí publicados. Trata-se da Revista Beira- Mar, para a qual ele colaborou entre os anos 1930 a 1943. A pesquisa foi feita também na hemeroteca digital. Trata-se, portanto, de uma pesquisa qualitativa e aplicada, cuja técnica principal foi a utilização de estratégia usada por muito tempo pela Filologia ou Crítica Textual: edição interpretativa.

Segundo Erich Auerbach (2015), a Filologia é o conjunto das atividades que se ocupam da linguagem do homem e das obras de arte escritas nessa linguagem. A preocupação em salvaguardar as obras do esquecimento e da degradação está presente desde a Antiguidade e, no século III a. C., surge a Filologia com o objetivo de editar os textos de Homero e de outros autores. Nesse sentido,

A necessidade de constituir textos autênticos se faz sentir quando um povo de alta civilização toma consciência dessa civilização e deseja preservar dos estragos do tempo as obras que lhe constituem o patrimônio espiritual; salvá-las não somente do olvido como também das alterações, mutilações e adições que o uso popular ou o desleixo dos copistas nelas introduzem necessariamente. (AUERBACH, 2015, p. 11).

Por essa perspectiva, cabe ao filólogo, além de estudar o documento, a tarefa de “[...] salvaguardar o patrimônio escrito, artístico e cultural, agir na recuperação, restauração, conservação e edição de textos (testemunhos-documentos-monumentos)." (SANTOS, 2008, p. 90). Ao filólogo cabe, sobretudo, propor novas leituras e interpretações.

A Filologia Textual, conforme Rosa Borges Carvalho (2003), tem por objeto de estudo o texto, tanto na sua existência material e histórica quanto na função de testemunho documental e literário. Sua tarefa consiste em resgatar os fios de transmissão dos textos, fazendo-se a inventariação e o estudo dos afastamentos da tradição face ao original, se ausente, através da crítica da tradição, se presente. 
Busca-se a lição mais próxima daquela que teve em sua origem, valorizando os materiais autênticos ou os seus vestígios, e os conhecimentos de que dispõe o filólogo no momento histórico em que trabalha.

Para César Cambraia (2005), a contribuição mais evidente e importante dessa ciência é a recuperação do patrimônio cultural escrito de uma dada cultura. Além disso, a Filologia contribui para a transmissão e a preservação desse patrimônio, colaborando para a transmissão dos textos, uma vez que, ao se publicar um texto, este torna-se novamente acessível ao público leitor; e contribui-se para sua preservação, porque se assegura sua subsistência através de registro de novos e modernos suportes materiais, que aumentarão sua longevidade.

Há diversas maneiras de tornar acessível ao público um texto. Sua edição pode ser em formato de bolso, comentada, fac-similar, abreviada, digital, etc. No campo da Filologia Textual, existem duas grandes categorias de edições: as monotestemunhais (baseadas em apenas um testemunho de um determinado texto) e as edições politestemunhais (baseadas no confronto de dois ou mais testemunhos de um mesmo texto). Como nossos testemunhos (em sua maioria) enquadram-se no primeiro grupo, optou-se pela edição interpretativa (além dessa, existem a fac-similar, a diplomática e a paleográfica). A edição interpretativa, segundo Rosa Carvalho (2003) é a edição crítica de um texto em que o editor o transcreve, corrige os erros por conjectura, registra no aparato todas as suas intervenções, atualiza a ortografia e elabora notas explicativas de caráter geral. As vantagens desse tipo de edição, de acordo com Cambraia (2005), são a de permitir apresentar o texto em uma forma acessível a um público amplo, além de oferecer a esses leitores um texto mais apurado, na medida em que os elementos estranhos à sua presumível forma genuína vêm claramente assinalados.

O trabalho desdobrou-se em três etapas. A primeira delas consistiu na identificação de todos os textos atribuídos a Galvão de Queiroz no corpus selecionado. Antes disso, porém, munimo-nos do aporte teórico que sustentou a pesquisa. Após a leitura do referencial teórico, passamos a identificar os textos no corpus selecionado. Antes da edição, fizemos a catalogação dos textos, baseados nos seguintes critérios, conforme quadro a seguir:

Quadro 1: Catalogação das obras de Galvão de Queiroz.

\begin{tabular}{|c|c|c|c|c|c|}
\hline \multicolumn{6}{|c|}{ CATALOGAÇÃO DAS OBRAS } \\
\hline No $^{\circ}$ & FONTE & $\begin{array}{c}\text { DATA DE } \\
\text { PUBLICAÇÃO }\end{array}$ & TÍTULO & GÊNERO & $\begin{array}{c}\text { COLUNA / PÁGINA/ } \\
\text { EDIÇÃO / NÚMERO }\end{array}$ \\
\hline 01 & O Município & $18 / 01 / 1936$ & Sortilégio & Crônica & $2^{\mathrm{a}}, \mathrm{p} .01, \mathrm{n}^{\circ} 03$ \\
\hline
\end{tabular}

Fonte: arquivo pessoal.

Após a catalogação, teve início a segunda etapa que consistiu na realização da edição interpretativa de todos os textos identificados no corpus, conforme aporte teórico da Filologia Textual. Para a edição, utilizamos os seguintes critérios: 1. Manter a pontuação original, levando em consideração o estilo do autor; 2. Enumerar os textos, linha a linha, indicando de cinco em cinco; 3. Quando poemas, conservar a distribuição do texto em estrofes, conforme o original; 
4. Atualizar a grafia, conforme as normas vigentes a partir do Acordo ortográfico em vigor; 5. Organizar os textos de acordo com a cronologia de sua publicação; 6. Indicar, em rodapé, a fonte do texto editado; 7. Ser fiel ao texto original; 8. Manter as opções tipográficas do autor quanto ao uso do itálico, negrito e aspas; 9. Manter o seccionamento dos textos e a estruturação dos parágrafos (quando em prosa) conforme o original.

A última etapa (ainda não finalizada), por sua vez, consiste na leitura e crítica do material coletado e editado. Nesse momento, além do perfil biográfico do autor, apresentaremos um estudo sobre sua obra, identificando as principais marcas estilísticas e temáticas aí presentes. Para finalizar essa última etapa, construiremos uma espécie de dossiê, por nós intitulado de Caderno Depositário, contendo os textos que serão editados, acompanhados desse estudo crítico. Além disso, esse caderno trará os dados do projeto, uma introdução feita pelo orientador, uma descrição do arquivo, além de uma apresentação com breves notícias dos jornais. Este material será encadernado com capa dura, terá catalogação no ISBN e será impresso para distribuição aos pesquisadores e aos responsáveis pelos acervos que facilitaram nossa pesquisa.

\section{As edições interpretativas e a preservação do patrimônio literário do Baixo Sul da Bahia}

Ao longo desse projeto, fizemos edição de quase duzentos textos de Galvão de Queiroz, dispersos em jornais, revistas e em duas Miscelâneas. Dentre esses textos, pudemos identificar crônicas, contos, poemas, poemas em prosa, entrevista, tirinhas e quadrinhos, texto dramático, traduções, crítica literária, textos informativos-científicos e um livro inteiro publicado sob a forma de folhetim, talvez o nosso maior achado. Além dos textos autorais, fizemos edição de outros cuja pauta era Galvão de Queiroz. Nosso objetivo foi recolher esse material a fim de construir um dossiê biográfico. Nesse material, aparecem notícias sobre o autor e sua família (filhos e outros parentes), informações sobre premiações, críticas sobre sua obra e notícias de publicações. Isso tudo será juntado no Caderno Depositário, a fim de ajudar a contar a biografia de Queiroz.

Por meio deste trabalho, pudemos reunir e editar textos dispersos de Innocencio Galvão de Queiroz, um dos maiores cronistas da cidade de Valença do século XX. Do ponto de vista científico, este projeto foi relevante naquilo que concerne à sua utilidade na preservação do patrimônio cultural e na oferta de subsídios para outros pesquisadores. Pioneiro nessa perspectiva, abrimos frentes de pesquisa nessa área temática, incentivando a preservação da memória cultural e literária na cidade. Outro impacto dessa proposta está diretamente atrelado aos seus objetivos. A recuperação e a preservação dos textos, por meio da edição aqui realizada, ajudam a compreender os costumes, as ideologias de uma época e a flagrar a língua em uso. O texto deve ser lido como testemunho de uma sociedade, de fatos particulares da história e, enquanto documento, é a prova que se tem dos fatos que marcaram a sociedade valenciana no século XX. Enquanto monumento, esse texto transmite e mantém viva a memória da cidade. Ademais, resgatar textos do autor em questão implica reinserir no campo literário um ficcionista de visibilidade nacional esquecido pelo cânone. A pesquisa, portanto, impactou 
diretamente nessa lacuna da história literária baiana e nacional, oferecendo a outros estudiosos textos até então desconhecidos do grande público. Nesse sentido, contribui - significativamente - para a construção de um outro capítulo da História da literatura baiana, ao editar, ler e perfilar vida e obra de um escritor que tanto contribuiu para a cultura local.

Apresentamos, como amostra do que foi desenvolvido ao longo do projeto, uma edição interpretativa de um poema encontrado na Revista Beira-Mar, datado de 1930. Antes, porém trazemos o fac-símile da página em que o texto foi publicado.

cDisponível em: <http://memoria.bn.br/DocReader/docreader.aspx?bib=067822\&pesq=\&pagfis=2386>

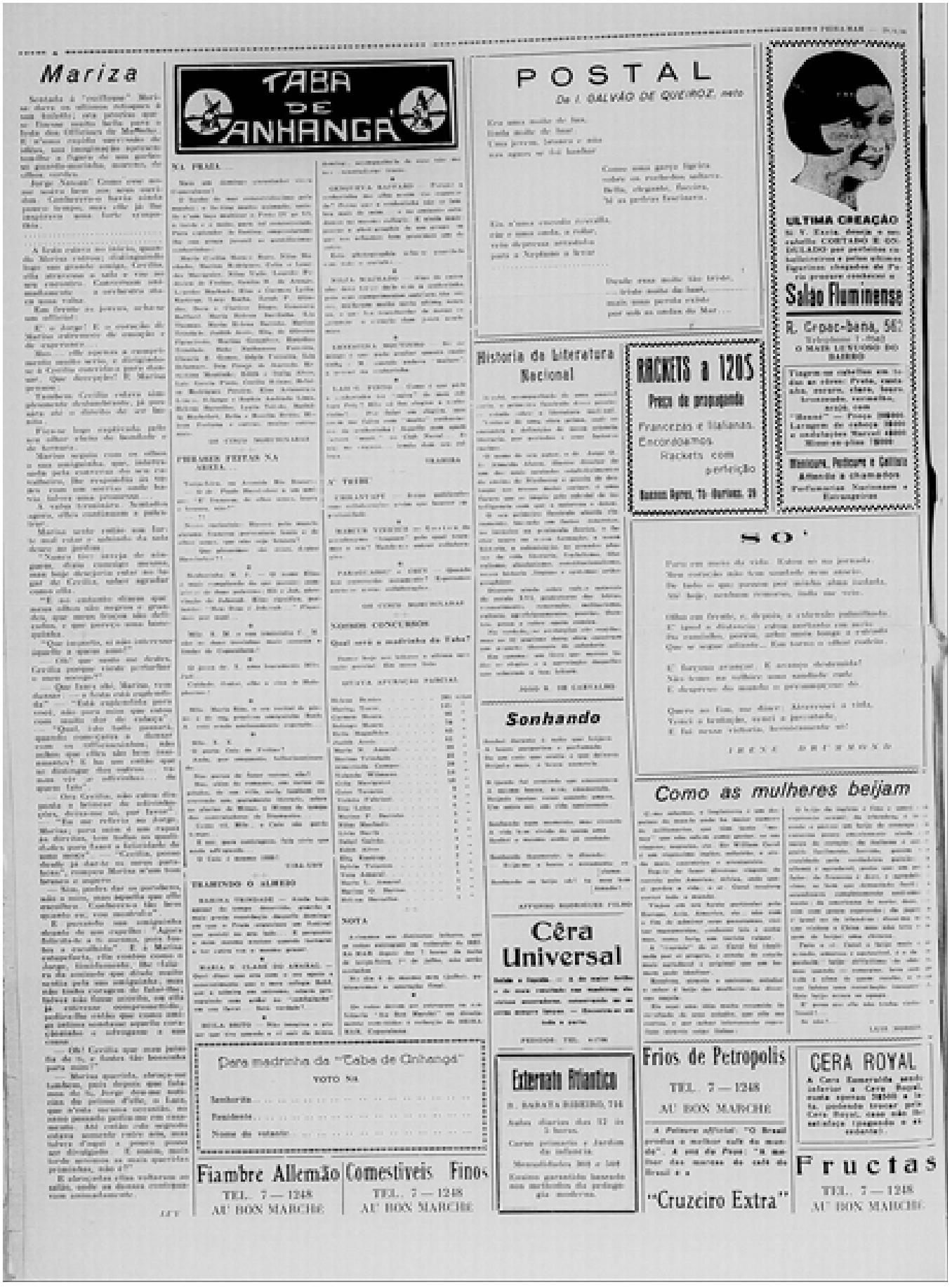


A seguir, apresentamos a edição interpretativa do poema Postal, publicado na revista supracitada. Trata-se de um poema composto por quatro estrofes, construídas em forma de quadras ou quartetos (estrofes de quatro versos), com cada verso apresentando sete sílabas poéticas (redondilha maior ou heptassílabos).

Figura 3: Poema publicado na Revista Beira-Mar, 29 de junho de 1930, n² 225, p. 4.

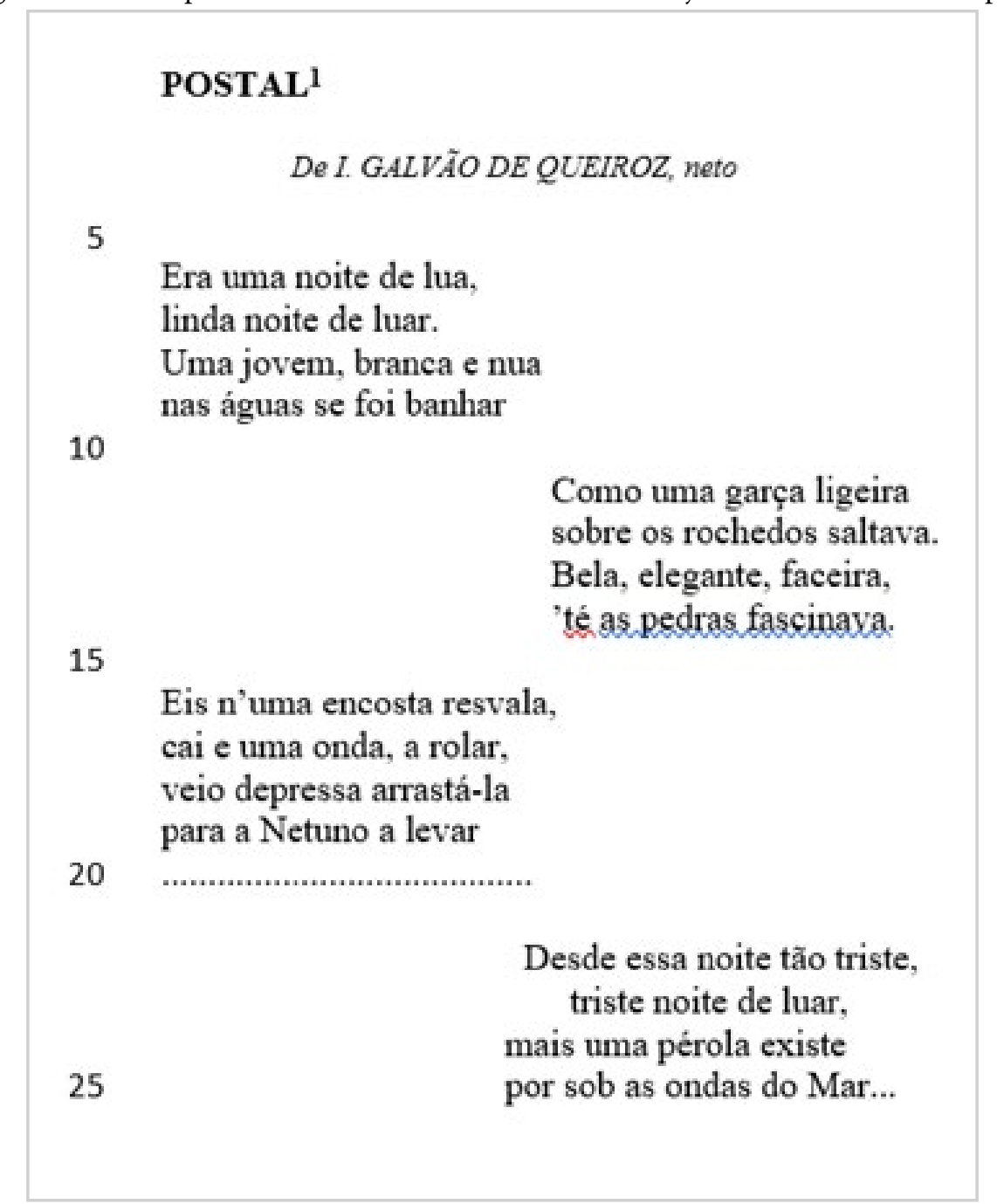

Fonte: Acervo da pesquisa.

Nessa edição, seguimos os critérios adotados para realizar as edições de modo geral. Mantivemos a pontuação original, enumeramos o texto em linhas, indicando de cinco em cinco. Por se tratar de poema, conservamos a sua distribuição em estrofes, segundo a orientação disposta no original. Fizemos algumas atualizações na grafia de certas palavras como núa > nua (linha 08), aguas > águas (linha 09), Bella > Bela (linha 13), resvalla $>$ resvala (linha 16), cáe > cai (linha 17), arrastal-a > arrastá-la (linha 18), Neptuno > Netuno (linha 19), perola > pérola (linha 24). Mantivemos a linha pontilhada separando a última da penúltima estrofe e conservamos a grafia da palavra Mar em maiúscula no último verso. Por fim, indicamos, em rodapé, a fonte do texto editado e mantivemos algumas variantes não formais que aparecem no poema: 'té (linha 14) e n'uma (linha 16). 
Preservar o patrimônio artístico e cultural de uma cidade é necessário, já que ele é testemunho vivo da herança cultural de gerações passadas que, por sua vez, exerce papel fundamental no tempo presente e se projeta para o futuro, transmitindo às gerações vindouras as referências de um tempo que jamais serão retomadas ou revividas, mas que podem ser revisitadas, criando uma consciência da intercomunicabilidade da história.

Segundo Le Goff (1990), a memória, ao conservar certas informações, contribui para que o passado não seja totalmente esquecido e faz com que a história se eternize na consciência humana. Esse passado, portanto, só permanece vivo por meio de trabalhos de síntese da memória. Ainda para esse autor, a memória estabelece vínculos entre as gerações humanas. Tais laços possibilitam que a população passe a enxergar-se como sujeito da história e cidadão de uma determinada localidade. Portanto, por meio da preservação da memória cultural, traçam-se identidades e se fortalecem os laços de cidadania de um povo, construindo aquilo que Pellegrini (2006) denomina de ethos cultural.

De acordo com Woodward (2000), a redescoberta do passado é parte do processo de construção de identidade, uma vez que, por meio dos antecedentes históricos, as identidades também se estabelecem. Nesse sentido, a simples busca de elementos do passado para afirmar identidades pode produzir novas identificações e forjar novos processos de subjetividades.

Tomando esses pressupostos como parâmetros, sustentamos a contribuição social do nosso projeto e reiteramos a importância de sua realização. Recuperar o passado, conforme já apontamos, ajuda a fomentar identidades, a fortalecer o sentimento de pertencimento ao locus onde se vive e aguçar o espírito de cidadania. Com esta pesquisa, por meio de seus produtos, além de recuperar o patrimônio literário, iremos devolver à cidade o material do autor que fora esquecido, fomentando a valorização da literatura local, contribuindo para a valorização das identidades locais e reintroduzindo o autor no cenário literário baiano e nacional.

\section{Considerações finais}

Buscou-se, neste texto, apresentar um projeto de pesquisa cujo intuito foi o de preservar e valorizar o patrimônio literário da cidade de Valença e do Baixo Sul da Bahia. Por meio das edições interpretativas, recuperamos textos dispersos de Galvão de Queiroz, reunindo e oferecendo ao público textos desse autor até então desconhecidos ou, sobretudo, esquecidos pelas pessoas. A principal contribuição da Crítica Textual consiste na recuperação do patrimônio cultural escrito de uma dada cultura. Com este projeto, contribuímos para essa função, ao localizar quase duzentos textos do autor dispersos em jornais locais, revistas nacionais e, principalmente, em cadernos particulares.

Outra contribuição da Crítica Textual é a transmissão e a preservação do patrimônio, quando, após cada edição, publica-se o texto e, novamente, torna-o acessível ao público leitor, reativando a memória do texto e do autor. Com nosso trabalho, trazemos, à luz, uma série de textos de Galvão de Queiroz e o reintroduzimos no cenário crítico local e nacional, divulgando sua obra e disponibilizando-a para outros pesquisadores. 
Esse trabalho filológico é também um trabalho de resgate da memória e de afirmação e/ou reforço de identidades. Por meio dessas edições realizadas, salvaguardamo-las, evitando o seu esquecimento. Sobreviveram, resistiram, com tudo isso, o texto, o autor, a memória e as identidades.

\section{Referências}

AUERBACH, Erick. Introdução aos estudos literários. Tradução de José Paulo Paes. São Paulo: Cosac Naify, 2015.

CAMBRAIA, César Nardelli. Introdução à crítica textual. São Paulo: Martins Fontes, 2005.

CARVALHO, Rosa Borges Santos. A Filologia e seu objeto: Diferentes Perspectivas de Estudo. Philologus

- Revista do Círculo Fluminense de Estudos Filológicos e Lingüísticos, ano 9, n.26, Rio de Janeiro. 2003.

COLOMBO, Fausto. Os arquivos imperfeitos. São Paulo: Perspectiva, 1991.

DERRIDA, Jacques. Mal de arquivo: uma impressão freudiana. Tradução de Cláudia de Moraes Rego. Rio de Janeiro: Relume Dumará, 2001.

GRÉSILLON, Almuth. Devagar: obras. In: ZULAR, Roberto (Org.). Criação em processo: ensaios de crítica genética. São Paulo: Iluminuras, 2002, p. 147-74.

LE GOFF, Jacques. História e memória. Campinas, SP: Unicamp, 1990.

NORA, Pierre. Entre memória e história: a problemática dos lugares. Projeto História. São Paulo: PUC-SP. N 10, p. 12. 1993.

PELEGRINI, Sandra C. A. Cultura e natureza: os desafios das práticas preservacionistas na esfera do patrimônio cultural e ambiental. In: Revista Brasileira de História. São Paulo 2006, v. $26, \mathrm{n}^{\circ} 51$, p. $115-140$.

SANTOS, Rosa Borges dos. Uma metodologia aplicada à edição de textos teatrais. In: MAGALHÃES, José Sueli de; TRAVAGLIA, Luiz Carlos (Org.). Múltiplas perspectivas em linguística. Uberlândia: Edufu, 2008. 1 CD-ROM. p. 2663-2670.

SOUZA, Eneida Maria de. Crítica cult. Belo Horizonte: Editora UFMG, 2002.

WOODWARD, K. Identidade e diferença: uma introdução teórica e conceitual. In: SILVA, T. T. (Org.). Identidade e diferença - a perspectiva dos estudos culturais. Petrópolis, RJ: Vozes, 2000. 